\title{
Business Interoperability on E-Marketplace
}

\author{
Jingzhi Guo \\ Department of Computer and Information Science, University of Macau Av. Padre Tomás \\ Pereira, S. J. Taipa, Macau, P.R. China jzguo@umac.mo
}

\begin{abstract}
The increasing demand for doing business online calls for higher business interoperability on e-marketplaces (EMp). This drives the development of integration technologies for improving EMp functions. This paper argues that by comparing the cost of business interoperability on EMp brought by the integration technology, firms will more favour joining in public EMp than selfbuilding private EMp. In this shift, three integration factors of standard flexibility, service provision and semantic integration are constantly improving EMp functions, which lead to an overall reduction of interaction cost for business interoperation. This will change business behaviours and corporate strategies of most firms and have important implications for firms to make strategies of how to treat EMp to increase business interoperability.
\end{abstract}

Keywords: Electronic market place, Inter- enterprise interoperation, Business integration, Electronic husiness (E-business), E-commerce

\section{INTRODUCTION}

In the past two decades, the business integration technologies have undergone a drastic transition from internal functions integration within a firm to external marketplace functions integration between firms [14]. These innovations have radically reduced the cost and time of business interoperation within and between firms that require for information sharing, exchanged data understanding and underlying systems integration [5]. This, in turn, brought many changes in the ways emarketplaces are built and used. Underlying these changes are more fundamental changes in how firms adopt their e-marketplace patterns to connect with each other for rebuilding value-added chains online. In this paper, we address more basic issue of how advances in integration technologies developed in the context of e-commerce are affecting the business interoperability on e-marketplaces and discuss the options these changes present for corporate strategies.

Electronic marketplace (EMp) is a product of Internet computing technology and is one of the quickest development areas of e-commerce. It is a common information space [7], where e-business information exchange is enabled to allow EMp functions to be presented with certain information exchange efficiency and/or financial cost in use. With a historical perspective [7], the development of EMp was highly related to

Please use the following format when citing this chapter:

Guo, J., 2007, in IFIP International Federation for Information Processing. Volume 254, Research and Practical Issues of Fnterprise Information Systems II Volume 1. eds. I. Xu. Tjoa A., Chaudhry S. (Boston: Springer), pp. $257-267$. 
the development of integration technology, from an intra-enterprise EMp (e.g. a tradition ERP system integrating discrete departments to enable better information exchange), to an inter-enterprise EMp (e.g. a community-oriented SCM system integrating heterogeneous firms for inter-enterprise information exchange), and to a regional or a global EMp (e.g. a global trading system like Alibaba.com integrating unknown firms to enable irregular international trade). Integration technology here can be defined as any type of IT technologies that enable better business information exchange on Internet between any business entities. Speaking from the levels of integration, these technologies can be the enablers of the exchanges of business concepts, documents and processes between either homogeneous or heterogeneous business applications or systems belonging to discrete business entities. It is obvious that the purpose of developing integration technologies is to provide a better business information exchange system, that is, a common business information space in terms of an EMp. Furthermore, the achievement of a better EMp is to improve the ability of business interoperation between any business entities, or in another word the business interoperability that can be defined as the capability of business collaboration between business partners for the fulfilment of certain business functions at certain cost and efficiency. Thus, a logical sequence can be found such that to improve integration technology is to formulate a more cost-effective EMp and finally is to increase business interoperability.

In this paper, we argue that new integration technologies lead to an imbalance development of EMp between public electronic marketplaces (public EMp run by an industry consortium or a third-party) and private electronic marketplaces (private $E M p$ run by a single firm), where the cost and time of joining in public EMp is tremendously improved. Thus, there is a shift towards the more joining in of public EMp than self-building private EMp, transferring more participants (i.e. facilitators [7] and/or users) from traditional markets or private EMp. Some innovative firms will become public EMp facilitators but not users. Many financially and technically strong firms will become the both facilitators and users of the private EMp tightly integrating their business partners. Most firms will benefit from the emergence of the new integration technologies for better business interoperability.

The analytical framework, on which our argument is based, follows the transaction cost theory $[12,23]$, which is useful in explaining the EMp pattern changes brought by the development of integration technologies, as well as predicting the consequences of the changing business interoperability. The past two decades provides some clue of integration technologies for us to understand how they impact on the changes of cost and efficiency of EMp construction and hence possibly change people's attitude on adopting different types of EMp.

\section{ANALYTICAL FRAMEWORK}

A precondition of online business is to establish and use e-channel between business partners [19]. The cost and efficiency of building and using the e-channels determine the business interoperability. The e-channels can be researched in the context of EMp such as e-portal [21] (e.g. Amazon.com, CTrip.com and Dell.com), e- 
hub [18] (e.g. Tradecard.com and Alibaba.com), or simply an Internet-based software package sold to firms to form supply chain (i.e. e-package as we called, e.g. SAP SCM systems or global trading systems). For all these EMp forms, the business interoperability on them is measured by the cost and efficiency of these EMp's available business functions such as the services of matching buyers and sellers, facilitation of transaction, and institutional infrastructure [10].

In this section, we propose our framework to state that EMp participants tends to more favour one type of EMp if its use cost for achieving business interoperability is less than that for using another type of EMp.

\subsection{Definitions of Private EMp and Public EMp}

EMp has two basic forms for achieving business interoperability [15]: public EMp or many-to-many public exchanges, and private EMp or one-to-one/one-to-many private exchanges. A general decision that a firm has to make is whether it should join in a public EMp or self-build a private EMp to increase the same business interoperability. Public EMp is a business information exchange mechanism that provides the business interoperability between firms and is run by an e-marketplace facilitator, such as an industry consortium or a third-party dot-com firm (e.g. plasticsnet.com), to orient towards a perfect market for a group of buyers and sellers. It strives to reach industry- and market-based efficiency through managing interactions among EMp users. The EMp Facilitators as third-party determine the provided exchange functions based on the market demand, legal environment, profitability and maturity of EMp technologies. Firms using the public EMp could compare the cost and benefit of the available business interoperation functions between all public EMp and choose the one that is best appropriate to them. The major thought of adopting a public EMp by firms for business interoperability is that, by means of building a closer external partner relationships through service outsourcing, firms can be reconstructed as a light-weighted organization and thus decrease the management overhead. Private EMp, on the other hand, is a business information exchange mechanism for business interoperability within a firm (i.e. a firm acting as both EMp facilitator and a sole EMp user) by means of merging more external exchange partners. It is driven by a single seller or buyer and typically involves a firm automating its own supply chain and customer base where participation is generally open to suppliers or customers of the firm. Firms that have perfected this model include Dell, Cisco, and Wal-Mart. The philosophy behind it is that the excellence of management technique can make business interoperation more efficient by building a self-owned EMp than the external use of one or more thirdparty EMp, because the cost and time of coordinating external technical, social and legal relationships could be minimized. In addition, customer loyalty and trusted partner relationships can be maintained.

Variants or different naming of the two pure forms for business interoperability exist (e.g. auctions, vertical and horizontal exchanges, e-portals, e-hubs and community exchanges), but can usually be categorized into the above two forms. In general, when a technically and/or financially strong firm is a dominant seller or buyer in markets, it tends to increase business interoperability through a self-owned 
private EMp, for example, Boeing Company [20]. On the other hand, when a firm is both financially and technically weak such as small and medium sized enterprises (SMEs), it often favours to be the users of public EMp (e.g. users of Alibaba.com) to increase business interoperability, because this form offers more opportunities for finding potential buyers and creditable sellers.

\subsection{Factors Favouring Public and Private Electronic Marketplaces}

Following the transaction cost theory $[23,12]$, the EMp can be discussed in terms of management costs and interaction costs. The management costs refer to the costs of the setup, maintenance and use of an EMp, while the interaction costs denote the costs of purchase, integration and use of an EMp. Adopting the comparative advantage theory [17] often used in economics, a general statement can be derived such that trade-offs exist between firms with regard to the management costs and interaction costs, assuming that the equal business interoperability is desired (i.e. same efficiency and quantity of EMp functions at cost) by the EMp participants. The comparison between the two types on costs is opportunistic, which determines the intent of a firm on selecting either private EMp via building by itself or public EMp by joining in as a user. Table 1 summarizes the statement relevant to our argument.

Table 1. Relative Cost for Private and Public EMp

\begin{tabular}{|l|c|c|}
\hline & $\begin{array}{c}\text { Management } \\
\text { Cost }\end{array}$ & $\begin{array}{c}\text { Interaction } \\
\text { Cost }\end{array}$ \\
\hline $\begin{array}{l}\text { Private EMp (self-building as a single buyer or } \\
\text { seller) }\end{array}$ & High & Low \\
\hline $\begin{array}{l}\text { Public EMp (joining in as a competitive buyer or } \\
\text { seller) }\end{array}$ & Low & High \\
\hline
\end{tabular}

In Table 1, the "Low" and "High" give a relative comparison of management cost and interaction cost between private EMp and public EMp. They reflect the comparative advantages and disadvantages of each specific EMp. For private EMp, the advantages are that a firm is not necessary to purchase the membership from public EMp and spend any money to integrate its own business systems to the external heterogeneous public EMp systems. The disadvantages are its own bearing of the costs by the firm for the EMp setup and maintenance. For public EMp, the advantages are that a firm has no need to cost its own to setup and maintain a specialized EMp for business interoperation. Its disadvantages are the firm's costs of purchasing the EMp services and the integration of its business systems into the accessed EMp. What's more, the public EMp themselves may not be well functionally integrated to provide business interoperability, e.g. the failure lesson from CommerceOne [6], which provided immature public EMp technology.

Table 1 is consistent with the traditional analysis of electronic hierarchy and electronic markets [12], where the concept is opportunistic. In this analysis, the choice 
between private EMp and public EMp depends on the cost by comparing the management costs and interaction costs between the two EMp. If an EMp offers lower cost than another, it would be favoured by the related firms.

There are many factors that affect cost hence the choice between private EMp and public EMp for business interoperation, such as information privacy, customer loyalty, trust relationship, market power, financial strength and technical ability. Other things remaining unchanged, two factors play an important role in comparing costs. They are business standard flexibility and business concept complexity. The issue of business standard flexibility has been discussed in the researches of standard integration $[1,12]$ while the reduction of business concept complexity has been investigated in ontology-based approach $[11,10]$, community-based/usage-centric technique (WebCatalogPers) [16], and collaboration-based/concept-centric approach (CONEX) [8].

Business standard flexibility. Business standard can be classified as international standards (e.g. UNSPSC.org), de facto industrial standards (e.g. ebXML.org), enterprise standards (i.e. used within a firm), and non-standards that most SMEs adopt. Business standard flexibility refers to the application ability of a standard from a given scope to another scope. It is an ability of integrating the internal legacy business systems into the external heterogeneous systems. Its opposite term business standard rigidity that can be compared with the concept of asset specificity [12] such that the latter emphasizes on the movability of physical goods off Internet while the former focuses on the exchangeability of electronic data on Internet. Business standards are the most important building blocks of EMp for business interoperability such that one business system can interoperate with another by following the same standards. However, business standard rigidity becomes an issue, because the desired increasing business interoperability asks for the more and more flexibility of business standards to adapt to a wider scope of integrating more distributed and more heterogeneous e-business systems.

Due to the above reason, a firm often favours to achieve business interoperability on a private EMp if it has a set of rigid enterprise-wide business standards and more depends on these legacy standards. This is because the change of existing rigid business standards in use will pay a higher cost for interaction than for management in e-business systems integration. In contract, firms in general favour to achieve business interoperability on public EMp if they have flexible business standards or they are less dependent of these legacy standards. This is because the cost paid to integrating their e-business systems into the public EMp is less than the cost of building their own private EMp for the same level of business interoperability.

Business concept complexity refers to the amount of effort for representing and using the syntactically and semantically interoperable business concepts. A business concept denotes a broad business connotation including the presentation and use of a business vocabulary, a business document, a business processes and even a whole business service [9]. For example, a business process is a sequence of operation concepts operated on a set of business documents that are in exchange. A business document is a set of business terms and values. All these business processes, documents, terms and values are business concepts. The business concept complexity can be regarded as a critic extension to the traditional understanding of business complexity in terms of the complexity of product descriptions [12]. 
Other things being equal, a firm tends to achieve business interoperability on private EMp if it is able to reduce the business concept complexity by turning the systems of complex concept representation and use into the systems of simple concept representation and use. This is because a simpler system, which can maintain the same business interoperability, is less in financial cost. For example, if a firm like Boeing Company [20] can force its business partners to adopt a uniform business concept representation system that is consistent with its legacy business systems (i.e. simplify the overall system in the eye of Boeing), it will be no doubt that a private EMp will be favoured by Boeing. In contrast, a firm favours to achieve business interoperability on public EMp if it is unable to handle the business concept complexity or there are no legacy business concept representation systems. This is because the handling financial cost of complex business concepts is much higher in maintaining or creating a private EMp by itself than simply joining in a ready-made public EMp. For instance, SMEs have non-standard business concept representation systems, which are most complex in business concept integration. They are also technically and financially weak in building private EMp for handling complex business concepts. What's more, they are less influential in forcing its business partners to join in their private EMp if any. Thus, SMEs, in general, seek public EMp to achieve their business interoperability.

Figure 1 shows that when a firm has more flexible business standards and is unable to reduce business concept complexity, it tends to use public EMp for business interoperability. In contrary, when a firm has more rigid business standards and is able to reduce business concept complexity, it tends to adopt private EMp for business interoperability.

\section{INTEGRATION TECHNOLOGY AND ITS IMPACTS}

The development of integration technology is changing the factors of business standard flexibility and business concept complexity that affect the cost for choosing between public EMp and private EMp for achieving business interoperability. This reflects in three aspects of the development of flexible standards, the evolution of service provision, and the emergence of semantic integration, which are shown in Table 2, 3 and 4. 


\subsection{The Development of Flexible Standards for Electronic Marketplaces}

Table 2 shows that EMp standards for integration are moving from proprietary standards to open standards. This trend signifies that the standards are becoming more and more flexible. It implies that various e-business systems are easier to be integrated on EMp with less cost and time for interaction. This is because the open standard has proved its advantages in reusability and easy deployment [5].

Table 2. Development of Flexible Standards for EMp

\begin{tabular}{|c|c|c|}
\hline Evolving stage & proprietary standard & open standard \\
\hline Characteristics & pre-design, rigid & open, statically pre-designed \\
\hline $\begin{array}{l}\text { Examples and } \\
\text { cases }\end{array}$ & $\begin{array}{c}\text { EDIFACT } \\
\text { (www.unece.org/trade/untdid) }\end{array}$ & $\begin{array}{l}\text { UNSPSC, ecl@ss, etc. for business, and ebXML, } \\
\text { SOAP, WSDL, BPML etc. in interoperability } \\
\text { services }\end{array}$ \\
\hline Cost and time & $\begin{array}{l}\text { high cost in design \& long } \\
\text { time to deploy }\end{array}$ & $\begin{array}{l}\text { less time in design and less cost to deploy and } \\
\text { reuse }\end{array}$ \\
\hline
\end{tabular}

\subsection{The Evolution of Service Provision in Electronic Marketplaces}

Table 3 shows that the evolution of service provision from the cases of early rigid and non-reusable EDI systems to the open and highly reusable web services [3]. The evolving stages have proved that acquiring services from EMp (e.g. EDI systems, ASP networks, Web service oriented integration systems) is becoming easier and easier with less cost and time. It implies that EMp participants can find more desirable services through the outsourcing in public EMp, and there is no necessity to design and build any private EMp by their own.

Table 3. Evolution of Service Provision in EMp

\begin{tabular}{|c|c|c|c|}
\hline Evolving stage & $\begin{array}{c}\text { electronic connection } \\
\text { and EDI }\end{array}$ & $\begin{array}{c}\text { application service } \\
\text { provision (ASP) }\end{array}$ & web service (WS) \\
\hline Characteristics & $\begin{array}{l}\text { - one-to-one connection } \\
\text { - trusted partners on VPN } \\
\text { - data transaction on ANSI } \\
\text { X12 and Edifact for inter- } \\
\text { and intra-industry } \\
\text { - connectivity with trade } \\
\text { documents } \\
\text { - governed by standards of } \\
\text { specific industry } \\
\text { consortium }\end{array}$ & $\begin{array}{l}\text { - one-to-many connection } \\
\text { - trusted partncrs on } \\
\text { proprictary network } \\
\text { - data transaction on } \\
\text { proprietary standards } \\
\text { - connectivity with trade } \\
\text { documents } \\
\text { - governed by standards of } \\
\text { vendors }\end{array}$ & $\begin{array}{l}\text { - many-to-many connection } \\
\text { - dynamically joined partners } \\
\text { on Internet } \\
\text { - Data transaction on XML } \\
\text { SOAP in WSDL } \\
\text { - connectivity with } \\
\text { application-to-application } \\
\text { - governed by standards of } \\
\text { W3C, OASIS and WS-I }\end{array}$ \\
\hline $\begin{array}{l}\text { Examples and } \\
\text { cases }\end{array}$ & $\begin{array}{l}\text { - electronic connection e.g. } \\
\text { American Hospital Supply } \\
\text { Corporation (AHS) to many } \\
\text { hospitals (1970s) } \\
\text { - built-in house EDI c.g. }\end{array}$ & $\begin{array}{l}\text { - Web EDI (outsourcing) } \\
\text { eg.covalentworks.com, } \\
\text { dicentral.com, datatrans- } \\
\text { inc.com, spscommerce.com. } \\
\text { - outsourcing enabled }\end{array}$ & $\begin{array}{l}\text { - WebserviceX.net } \\
\text { - Oracle: www.oracle. } \\
\text { com/technology/tech/webserv } \\
\text { ices; IBM: www-128.ibm. } \\
\text { com/developerworks/webser }\end{array}$ \\
\hline
\end{tabular}




\begin{tabular}{|l|l|l|l|}
\hline & $\begin{array}{l}\text { TRADANET/TRADACO } \\
\text { M (Ghobadian et al, 1994) }\end{array}$ & $\begin{array}{l}\text { application, e.g. } \\
\text { ariba.com, Autodesk.com, } \\
\text { Salesforce.com }\end{array}$ & $\begin{array}{l}\text { ices; Microsoft: msdn. } \\
\text { microsoft.com/webservices }\end{array}$ \\
\hline Cost and time & $\begin{array}{l}\text { - high cost in installation } \\
\text { and maintenance } \\
\text { - time-consuming for } \\
\text { deployment }\end{array}$ & $\begin{array}{l}\text { - configurable cost by } \\
\text { outsourcing } \\
\text { - less time in deployment }\end{array}$ & $\begin{array}{l}\text { - low cost in deployment } \\
\text { through increased reusability }\end{array}$ \\
\hline
\end{tabular}

\subsection{The Emergence of Semantic Integration on Electronic Marketplaces}

Table 4 shows that the emergence of semantic integration technology on EMp has characterized a path that the difficulties of business information exchange between heterogeneous e-business systems, or their conflicting business understanding, are gradually reducing. The overall cost and time of processing the business concepts with the same complexity is decreasing. This implies that the interaction cost between EMp participants is lowering.

Table 4. Emergence of Semantic Integration on EMp

\begin{tabular}{|c|c|c|c|c|}
\hline $\begin{array}{l}\text { Evolving } \\
\text { stage }\end{array}$ & keywords & metadata & ontologies & collaborative concepts \\
\hline $\begin{array}{l}\text { Characteri } \\
\text { stics }\end{array}$ & $\begin{array}{l}\text { - no semantic } \\
\text { conflict } \\
\text { resolution } \\
\text { - semantic } \\
\text { consistency } \\
\text { depends on } \\
\text { the hidden } \\
\text { meanings }\end{array}$ & $\begin{array}{l}\text { - pre-designed } \\
\text { semantic consistency } \\
\text { on meta-data level } \\
\text { - semantic conflicts on } \\
\text { data level }\end{array}$ & $\begin{array}{l}\text { - pre-designed } \\
\text { semantic consistency } \\
\text { for all terms in one or } \\
\text { several integrated } \\
\text { ontologies } \\
\text { - concept and concept } \\
\text { value are not separated }\end{array}$ & $\begin{array}{l}\text { - collaboratively designed } \\
\text { semantic consistency for all } \\
\text { concepts } \\
\text { - partially resolved semantic } \\
\text { conflicts for concept values } \\
\text { - separate concepts from } \\
\text { concept value }\end{array}$ \\
\hline $\begin{array}{l}\text { Examples } \\
\text { and cases }\end{array}$ & $\begin{array}{l}\text { - search } \\
\text { engines, e.g. } \\
\text { Yahoo.com, } \\
\text { Google.com, } \\
\text { Microsoft.co } \\
\text { m, } \\
\text { Altavista.com }\end{array}$ & $\begin{array}{l}\text { - organize resource } \\
\text { and specify search, } \\
\text { e.g. CERES/NBII } \\
\text { (ceres.ca.gov/thesauru } \\
\text { s/), MMUG } \\
\text { (marinemetadata.org) }\end{array}$ & $\begin{array}{l}\text {-ontology } \\
\text { management: } \\
\text { AlphaWorks (www. } \\
\text { alphaworks.ibm.com/t } \\
\text { ech/snobase) } \\
\\
\text {-ontology editing, e.g. } \\
\text { protege.stanford.edu }\end{array}$ & $\begin{array}{l}\text { - collaborative concept } \\
\text { creation systems, e.g. } \\
\text { CONEX (www.sftw.umac. } \\
\text { mo/ jzguo/pages/ConexDem } \\
\text { o/index.html }\end{array}$ \\
\hline $\begin{array}{l}\text { Cost and } \\
\text { time }\end{array}$ & $\begin{array}{l}\text { - additional } \\
\text { cost and time } \\
\text { for resolving } \\
\text { semantic } \\
\text { conflicts from } \\
\text { hidden } \\
\text { meanings }\end{array}$ & $\begin{array}{l}\text { - additional cost and } \\
\text { time to maintain } \\
\text { semantic consistency } \\
\text { between metadata and } \\
\text { resolving data-level } \\
\text { semantic conflicts }\end{array}$ & $\begin{array}{l}\text { - additional cost and } \\
\text { time for integrating } \\
\text { heterogencous } \\
\text { ontologies and } \\
\text { resolving semantic } \\
\text { conflicts from } \\
\text { monolithic terms }\end{array}$ & $\begin{array}{l}\text { - distributed cost in } \\
\text { collaborative concept design } \\
\text { - lower cost and less time for } \\
\text { maintaining semantic } \\
\text { consistency between } \\
\text { heterogeneous concept } \\
\text { systems }\end{array}$ \\
\hline
\end{tabular}

The above changes in standards, service provision and semantic integration technologies have signified the following trends:

- Business standards are becoming more flexible, which becomes a strong drag of EMp participants to more favour just joining in public EMp than building private EMp by themselves. 
- Complex business concepts are becoming easier and cheaper to be processed in public EMp because of the new way of service provision and semantic integration.

These two trends support the argument that firms will more favour public EMp than private EMp for business interoperability with the development of integration technology.

\subsection{Impact of More Favouring Public EMp than Private EMp}

The more favouring public EMp than private EMp may have several important impacts on corporate behaviours and strategies.

- Firms will gradually abandon the practice of the full purchase of high cost hardware and software to set up a private EMp. Instead, they may buy reusable and interoperable business services from public EMp, because firms will find that this practice will save more costs.

- Strategic alliances will be formed between firms more than ever, because the purchase of non-core component services will be comparatively cheaper than the self-development in house, and it also increases the speed of time-tomarket to win the market competition.

- Collaborative design of various types of things such as business knowledge, products, processes and services will become popular, because the semantically integrated and enlarged EMp provides an unprecedented, global, collaborative, and virtual space for firms to work together.

- More firms will participate in public EMp, especially those SMEs that previously have no way of joining in EMp for sharing the benefit of business interoperability, because the entry fee for public EMp is drastically reduced to only membership fee but the working together functionality is increased.

Exceptions will continue to existing during the above shift. Large firms with strong market position and financial status such as Boeing Company [20] and DaimlerChrysler will continue to build and improve their own private EMp because it more complies with their corporate interests.

\section{CONCLUSION}

The integration technologies are proved more and more important to construct interoperable EMp for increasing business interoperability. The framework we have developed helps explain this change. We have seen that integration technologies have evolved along three major directions in standardization, service provision and semantic integration in a result of more flexible business standards and cheaper and easier of handling complex business concepts in public EMp. Such changes make the interaction cost on public EMp less and less and thus attract more and more firms from self-building of private EMp to joining in public EMp.

This shift has several implications for practitioners and technology developers: 
- Public EMp will not any more be a failure place in the case of CommerceOne [6]. All firms should realize the emerging business opportunities on public EMp brought by integration technology development.

- Most firms should consider certain forms of strategic alliances to benefit from the new advances of service provision supported by public EMp.

- Nearly all firms should be aware of the power of collaboration on EMp to increase corporate productivity.

- SMEs should seize the new opportunities by subscribing the integration services to join in public EMp for increasing their business interoperability.

In short, the development of integration technology, especially standardization, service provision and semantic integration, will lead to an overall increase of business interoperability on EMp, making firms more efficient and less cost in doing ebusiness on EMp.

The research conducted in this paper only describes the argument that firms will more favour joining in public EMp than self-building private EMp for business interoperability with the development of integration technology. The future work will verify this argument by an empirical research on the case analysis of the historical data from the selected EMp cases.

\section{REFERENCES}

1. T. Malone, J. Yates, and R. Benjamin, Electronic Markets and Electronic Hierarchies, Communications of the ACM. Volume 30, Number 6, pp.483-497, (1987).

2. R.H. Coase, The Nature of the Firm, Economica. Volume 4, pp.386-405, (1937).

3. Gilbert, Commerce One sells e-marketplace unit (9 December 2002). CNET News.com

4. M. Chen, A. Chen, and B. Shao, The Implications and Impacts of Web Services to E-

Commerce Research and Practices, Journal of Electronic Commerce Research. Volume 4, Number 4, pp.128-139, (2003).

5. R. Torrens, An Essay on the External Corn Trade (1815). http://cepa.newschool.edu/het/profiles/torrens.htm.

6. J. Leukel and G. Maniatopoulos, A Comparative Analysis of Product Classification in Public vs. Private e-Procurement, The Electronic Journal of e-Government. Volume 13, Number 4, pp.201-212, (2005).

7. P. Rossen, Electronic Trading Hubs: Review and Research Questions, Centre for International Business Studies, Dalhousie University, Canada (2001). http://cibs.management.dal.ca/n700-research.htm.

8. R. Sommer, T. Gulledge, and D. Bailey, The n-Tier Hub Technology, SIGMOD Record. Volume 31, Number 1, pp.18-23, (2002).

9. D. Ricardo, The Principles of Political Economy and Taxation, introduction by P.M. Fogarty (London: Dent \& Dutton, 1912).

10. Y. Bakos, The Emerging Role of Electronic Marketplaces on the Internet, Communications of the ACM. Volume 41, Number 8, pp.35-42, (1998).

11. T. Matz, Universal Business Integration: an Idea Whose Time has Come, Business Integration Journal. pp.10-13, (March, 2004).

12. C.S. Langdon and M. Shaw, Emergent Patterns of Integration in Electronic Channel Systems, Communications of the ACM. Volume 45, Number 12, pp.50-55, (2002). 
13. S.G. Thompson, M. Cioffi, H. Gharib, N. Giles, Y. Li, and T.D. Nguyen, From trips to telcos - next generation service portals, BT Technology Journal. Volume24, Number 1, pp.27-39, (2006).

14. H.Y. Paik, B. Benatallah, and R. Hamadi, Dynamic Restructuring of E-Catalog Communities Based on User Interaction Patterns, World Wide Web: Internet and Web Information Systems 5. pp.325-366, (2002).

15. E-Business Watch, e-Business Interoperability and Standards: a Cross-Sector Perspective and Outlook, Enterprise \& Industry Directorate General (European Commission, 2005).

16. S. Bergamaschi, F. Guerra, and M.Vincini, A Data Integration Framework for eCommerce, Lecture Notes in Computer Science. Volume 2342, p.379, 2002.

17. S. Lee, T. Lee, S. Lee, D. Lee, J. Kim, C. Lee, and J. Shim, Practical Issues for Building a Product Ontology System, in Proceedings of the 2005 Int'l Workshop on Data Engineering Issues in E-Commerce (DEEC'05) (IEEE Computer Society, 2005).

18. M. Hepp, The True Complexity of Product Representation, in Proceedings of 14th European Conference on Information System (ECIS 2006) (Sweden 12-14/06/2006).

19. J. Guo, Achieving Transparent Integration of Information, Documents and Processes, in Proceedings of IEEE Int'l Conf. on e-Business Engineering (ICEBE 2006) (IEEE Computer Society, 2006), pp.559-562.

20. C. Nøkkentved, Collaborative Processes in e-Supply Networks, ECoE Research Report, PriceWaterhouseCoopers (2000).

21. J. Guo and C. Sun, Global Electronic Markets and Global Traditional Markets, Electronic Markets. Volume 14, Number 1, pp.4-12, (2004).

22. J. Guo, Integration Ad Hoc Electronic Product Catalogues through Collaborative Maintenance of Semantic Consistency. PhD Thesis, Griffith University (2004). http://www4.gu.edu.au:8080/adt-root/public/adt-QGU20050824.125257/index.html.

23. Product Classification, in Proceedings of ISWC 2002 (LNCS 2342, 2002), pp.379-393.

24. E. Williamson, Markets and Hierarchies: Analysis and Antitrust Implications (Free Press: New York, NY, 1975). 